The INL is a

U.S. Department of Energy

National Laboratory

operated by

Battelle Energy Alliance

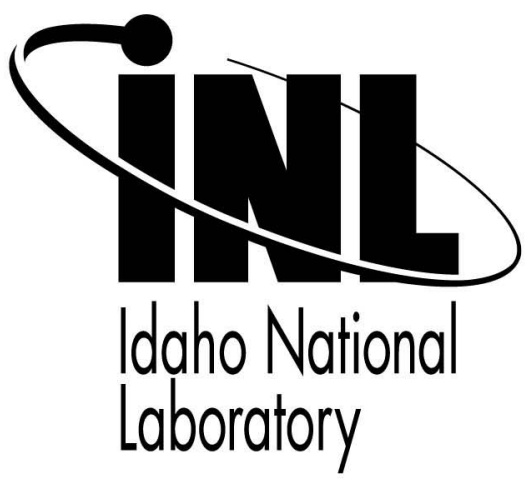

INL/CON-05-00458

PREPRINT

\title{
Measurement and Analysis of Gas Bubbles Near a Reference Electrode in Aqueous Solutions
}

\section{AIChE Annual Conference 2005}

\author{
Supathorn Phongikaroon \\ Steven D. Herrmann \\ Shelly X. Li \\ Michael F. Simpson
}

\section{October 2005}

This is a preprint of a paper intended for publication in a journal or proceedings. Since changes may be made before publication, this preprint should not be cited or reproduced without permission of the author. This document was prepared as an account of work sponsored by an agency of the United States Government. Neither the United States Government nor any agency thereof, or any of their employees, makes any warranty, expressed or implied, or assumes any legal liability or responsibility for any third party's use, or the results of such use, of any information, apparatus, product or process disclosed in this report, or represents that its use by such third party would not infringe privately owned rights. The views expressed in this paper are not necessarily those of the United States Government or the sponsoring agency. 


\title{
Measurement and Analysis of Gas Bubbles near a Reference Electrode in Aqueous Solutions
}

\author{
Supathorn Phongikaroon, ${ }^{*}$ Steven D. Herrmann, Shelly X. Li, and Michael F. Simpson \\ Pyroprocessing Technology Department, Idaho National Laboratory, Materials and Fuels Complex, MS 6180, \\ Idaho Falls, Idaho 83415
}

\begin{abstract}
Bubble size distributions (BSDs) near a reference electrode (RE) in aqueous glycerol solutions of an electrolyte $\mathrm{NaCl}$ have been investigated under various gas superficial velocities $\left(U_{\mathrm{s}}\right)$. BSD and voltage reading of the solution were measured by using a high-speed digital camera and a $\mathrm{pH} / \mathrm{voltage}$ meter, respectively. The results show that bubble size $(b)$ increases with liquid viscosity $\left(\mu_{\mathrm{c}}\right)$ and $U_{\mathrm{s}}$. Self-similarity is seen and can be described by the log-normal form of the continuous number frequency distribution. The result shows that $b$ controls the voltage reading in each solution. As $b$ increases, the voltage increases because of gas bubbles interrupting their electrolyte paths in the solutions. An analysis of bubble rising velocity reveals that Stokes' Law should be used cautiously to describe the system. The fundamental equation for bubble formation was developed via Newton's second law of motion and shown to be the function of three dimensionless groups-Weber number, Bond number, and Capillary number. After linking an electrochemical prineiple in the practical application, the result indicates that the critical bubble size is $\sim 177 \mu \mathrm{m}$. Further analysis suggests that there may be 3000 to 70000 bubbles generated on the anode surface depending on the size of initial bubbles and provides the potential cause of the effieiency drop observed in the practical application.
\end{abstract}

\section{Introduction}

The electrometallurgical treatment of spent nuclear fuel in a metal form has been demonstrated and is currently in operation at the Idaho National Laboratory (INL). This treatment is based on the anodic dissolution of an irradiated metal fuel in a molten salt electrolyte and the simultaneous deposition and recovery of uranium metal. ${ }^{1,2}$ The fission products are separated from the fuel in the process and are subsequently sequestered in engineered waste forms. ${ }^{3}$ To extend the electrometallurgical treatment technology to oxide-based fuels, a head-end operation is required to first reduce an oxide fuel to metal. Such a headend process is referred to as oxide reduction. In the oxidereduction process, uranium oxide is converted to uranium metal (cathode) and to oxygen gas (anode) by electrolytic means within a molten salt electrolyte $\left(\mathrm{LiCl}-\mathrm{Li}_{2} \mathrm{O}\right)$ at $650^{\circ} \mathrm{C} .{ }^{4,5}$ The electrochemical reactions for this process in making $\mathrm{U}$ metal are as follows:

$$
\begin{aligned}
& \text { Cathode: } \mathrm{UO}_{2}+4 \mathrm{e}^{-} \rightarrow \mathrm{U}+2 \mathrm{O}^{2-} \\
& \text { Anode: } 2 \mathrm{O}^{2-} \rightarrow \mathrm{O}_{2}(\mathrm{~g})+4 \mathrm{e}^{-} \\
& \text {Net reaction: } \mathrm{UO}_{2} \rightarrow \mathrm{U}+\mathrm{O}_{2}(\mathrm{~g})
\end{aligned}
$$

Despite extensive research and development of the oxidereduction process, there is still concern regarding the generation and adequate dispersion of oxygen bubbles from the anode, which potentially lower the cell efficiency because the bubbles will react to form $\mathrm{Li}_{2} \mathrm{O}$ if they are not removed from the system efficiently. This issue has not been thoroughly investigated and, therefore, provides the motivation to study the effect of physical properties and device geometry on gas-liquid interaction in the electrolytic reduction process. A fundamental mock-up study for this process has been designed in this investigation by generating bubbles through a glass frit in water and various

\footnotetext{
* Corresponding author. E-mail: supathom.phongikaroon $(\hat{a})$ inl.gov.
}

aqueous glycerol solutions at different flow rates. In addition, the reasons for choosing these liquid mediums relate to the physical properties of actual $\mathrm{LiCl}$ used in oxide-reduction operations.

The ultimate goal is to find a way of determining or predicting bubbles size in molten salt solutions in order to help monitor the process (events occurring in the oxide reduction). To advance closely toward this objective, this paper covers the work on (1) measurement and analysis of bubble size distribution (BSD), (2) its effect on the reference electrode voltage reading, and (3) the study of similitude to practical application.

First, a high-speed digital camera with image-analysis software was used to measure the BSD in aqueous solutions. Systematic experiments were conducted to determine the dependency of bubble size on the relevant physicochemical factors. Fundamental statistical analysis was applied. The bubble mean diameter $\left(b_{10}\right)$ and the area-weighted mean diameter $\left(b_{32}\right)$ were calculated to provide an interpretation of available data and to facilitate the discussion. A test of similarity was analyzed to examine the functional form of BSD based on these obtained statistical parameters.

Second, the percent relative difference (PRD) based on the baseline voltage reading from the reference electrode of the solutions at different conditions was calculated and correlated with mean bubble size. In this section, the idea is to find the impact of the mean bubble sizes on the voltage reading of the solutions obtained from the reference electrode. This information would help in predicting the bubble size in the closed system based on only the measured voltage reading values from the reference electrode in the solution.

Last, the recorded images were further used to calculate bubble rising velocity. Friction factor and flow regime were determined from bubble size based on physical properties of the system. In addition, these interpreted data were used to assist in developing a model for bubble formation via dimensionless groups and Newton's second law of motion incorporating electrochemical generation of gas and related to a practical application of the hot fuel dissolution apparatus (HFDA) 

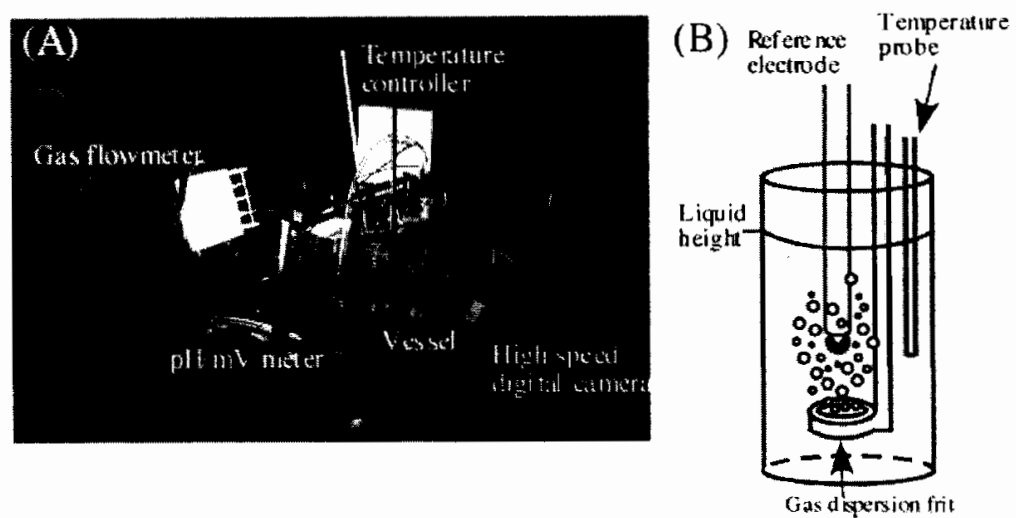

Figure 1. (A) Complete experimental setup for the bubble size distribution of oxygen gas generated near the reference electrode region and (B) schematic setup inside the vessel.

Table 1. Fluid Physical Properties at $25^{\circ} \mathrm{C}$

\begin{tabular}{lcccc}
\hline \multicolumn{1}{c}{ materials } & glycerol $(\mathrm{wt} \mathrm{\%})$ & density $\left(\mathrm{kg} / \mathrm{m}^{3}\right)$ & liquid viscosity $(\mathrm{mPa} \cdot \mathrm{s})$ & surface tension $(\mathrm{N} / \mathrm{m})$ \\
\hline oxygen & & $1.309^{b}$ & $0.0208^{b}$ & \\
water $(0.065 \mathrm{M} \mathrm{NaCl})$ & 0 & 999.4 & 0.909 & $0.0720^{a}$ \\
aqueous glycerol l $(0.065 \mathrm{M} \mathrm{NaCl})$ & 21.6 & 1052 & 1.70 & $0.0700^{a}$ \\
aqueous glycerol ll $(0.065 \mathrm{M} \mathrm{NaCl})$ & 38.8 & 1098 & 3.17 & $0.0684^{a}$ \\
aqueous glycerol llI $(0.065 \mathrm{M} \mathrm{NaCl})$ & 45.3 & 1113 & 4.81 & $0.0678^{a}$ \\
aqueous glycerol lV $(0.065 \mathrm{M} \mathrm{NaCl})$ & 56.9 & 1144 & 8.33 & $0.069^{a}$ \\
LiCl at $650^{\circ} \mathrm{C}$ & & $1480^{c}$ & $1.51^{c}$ & $0.134^{c}$ \\
oxygen at $650^{\circ} \mathrm{C}$ & & $0.422^{b}$ & $0.0353^{d}$ &
\end{tabular}

${ }^{\circ}$ Values are interpolated from Table 2.2 .1 in ref $6 .^{b}$ Density and viscosity values are obtained from ref $7 .{ }^{c}$ Values are obtained from ref $8 .{ }^{d}$ Value is calculated based on Chapman-Enskog theory from ref 6

operated at INL. Then, possible bubble formation and distribution in the electrochemical cell were interpreted and described from this information.

\section{Experimental Facility and Procedure}

The experimental system is shown in Figure 1. A cylindrical vessel had an inner diameter and a height of 8.3 and $20 \mathrm{~cm}$, respectively. The setup inside the vessel comprised an electrode (Ag/AgCl fluid-gel $\mathrm{KCl}$ fill solution, Accumet accuCap), a temperature probe, and a glass fritter $(40-60 \mu \mathrm{m}$ pores $)$. The reference electrode and the temperature probe were directly connected and recorded using Accumet Excel $20 \mathrm{pH} / \mathrm{mV} /$ conductivity meter. Oxygen bubbles were generated by dispersing them from a cylinder of pure oxygen through a glass fritter. Different gas flow rates were recorded using a Scienceware flowmeter. Temperature control was achieved by immersing the vessel in a rectangular acrylic open bath filled with water. The length, width, and depth of the reservoir were 46,26 , and 18 $\mathrm{cm}$, respectively. The water bath was kept at a constant temperature of $25 \pm 0.02{ }^{\circ} \mathrm{C}$ using a digital Fisher Isotempt immersion circulator.

To determine the relative significance of liquid-phase viscosity, oxygen bubbles were dispersed in five solutions of different viscosity $\left(\mu_{\mathrm{c}}\right), 0.909,1.70,3.17,4.18$, and $8.33 \mathrm{mPa} \cdot \mathrm{s}$, by using Nanopure water and four different glycerol solutions. $\mathrm{NaCl}$ was added to all solutions $(0.065 \mathrm{M} \mathrm{NaCl})$. The reason for adding $\mathrm{NaCl}$ was to provide a resemblance to the real system. Viscosities and densities were measured with Cannon-Fenske viscometers and a volumetric technique, respectively. The physical properties are listed in Table 1. As mentioned above, the reasons for using aqueous glycerol solutions were (1) to allow easy visualization of bubbles and (2) to ereate possible physical properties close to those of actual molten $\mathrm{LiCl}$ used in the actual processes (as listed in Table I for comparison).

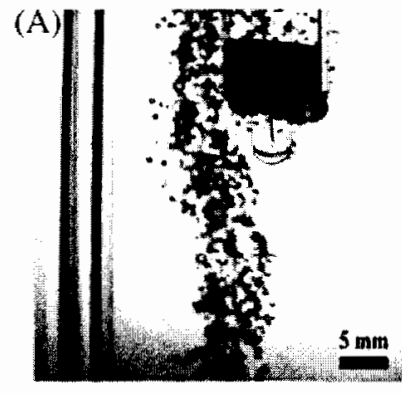

$b_{10}=563$ iun $\quad \sigma_{10}=131 \mu \mathrm{m}$

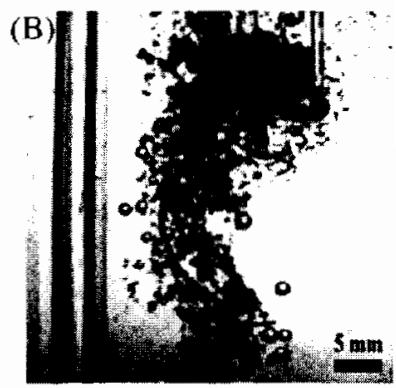

$\mathrm{b}_{10}=741 \mu \mathrm{m} \quad \sigma_{10}=295 \mu \mathrm{m}$
Figure 2. lmages of bubble dispersing in $8.33 \mathrm{mPa} \cdot \mathrm{s}$ solution and gas flow rates of (A) $13.2 \mathrm{~cm}^{3} / \mathrm{min}$ and (B) $74.1 \mathrm{~cm}^{3} / \mathrm{min}$.

The vessel was filled with $900 \mathrm{~cm}^{3}$ of the solution for each experimental run. Values of $\mathrm{pH} / \mathrm{mV}$ were recorded for $\sim 30 \mathrm{~min}$ to obtain the steady-state baseline value. After this measurement, oxygen bubbles were generated at seven different flow rates: $10.0,13.2,19.4,27.4,38.6,53.8$, and $74.1 \mathrm{~cm}^{3} / \mathrm{min}$. The system was allowed to reach equilibrium at each stage, which was typically $<5 \mathrm{~min}$. Therefore, after dispersing bubbles for $5 \mathrm{~min}$, $\mathrm{pH} / \mathrm{mV}$ were recorded and bubble images were captured at 500 frames/s using a high-speed imaging system (TroubleShooter 1000 by Fastec, Inc.). The experiment was performed three times for repeatability. After each process, the flow rate was increased and the system was again allowed to reach equilibrium. Recorded images were analyzed using MotionMeasure software suite to measure bubble sizes and to calculate their traveling velocities.

\section{Results and Discussion}

Upon review of the recorded images at $10 \mathrm{frames} / \mathrm{s}$, no breakup or coalescence of gas bubbles was observed in the analysis region (as shown in Figure 2). This observation is 

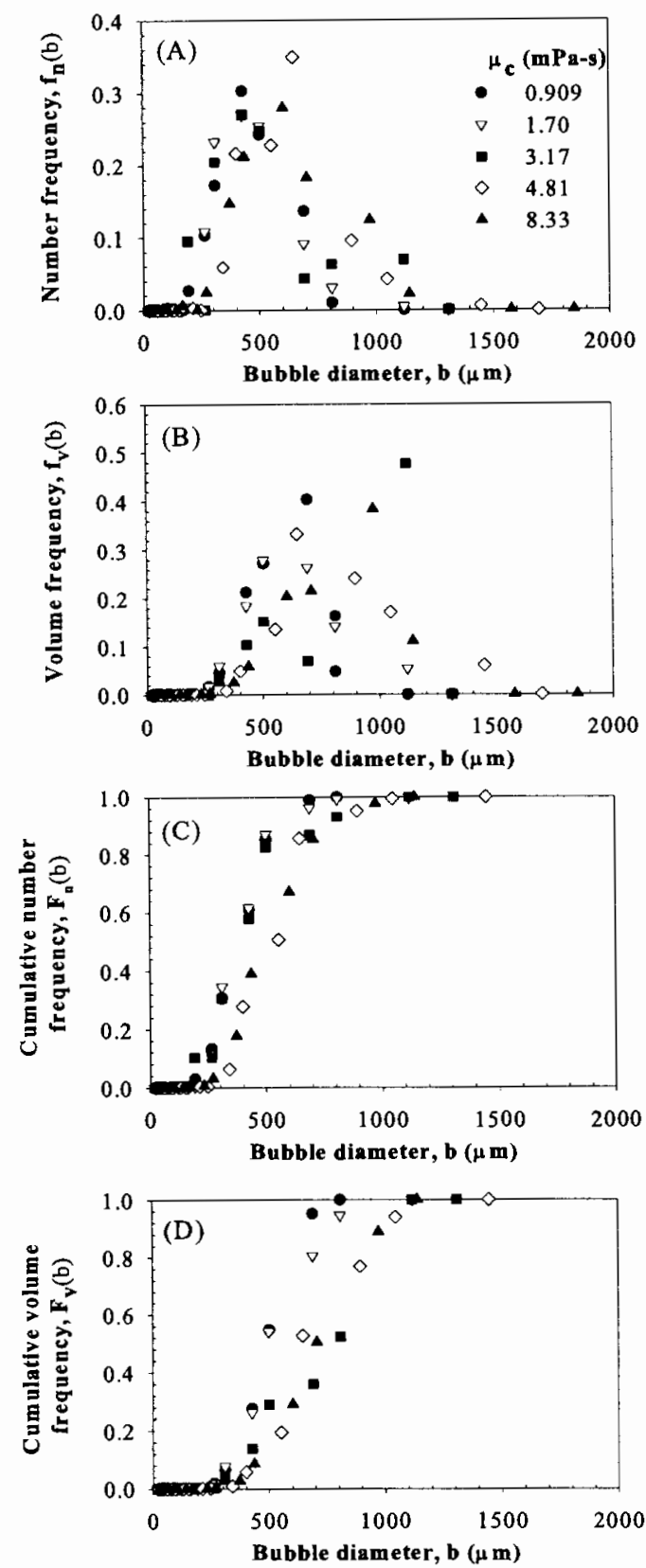

Figure 3. Effect of liquid viscosity on bubble size distribution at a gas flow rate of $19.4 \mathrm{~cm}^{3} / \mathrm{min}$ : (A) number frequency, (B) volume frequency, (C) cumulative number frequency, and (D) cumulative volume frequency.

consistent with a study by Lessard and Zieminiski ${ }^{9}$ showing the reduction of coalescence of gas bubbles within aqueous electrolytic solution by increasing both the amount of salt concentration and the viscosity. In addition, Prince and Blanch ${ }^{10}$ have reported that the breakup rate decreases significantly as $\mathrm{NaCl}$ concentration increases.

It is also important to point out that, since bubble dispersion is random, bubbles of various sizes can be generated. Therefore, the final equilibrium size distribution will contain a spectrum of bubble sizes. While information on maximum bubble size $\left(b_{\max }\right)$ is useful for some applications, more meaningful measurements of bubble size distribution are usually required. In fundamental statistical analysis, the mean bubble diameter $\left(b_{10}\right)$ and its varianee $\left(\sigma_{10}\right)$ are commonly used to facilitate the discussion. To determine the interfacial area per unit volume,
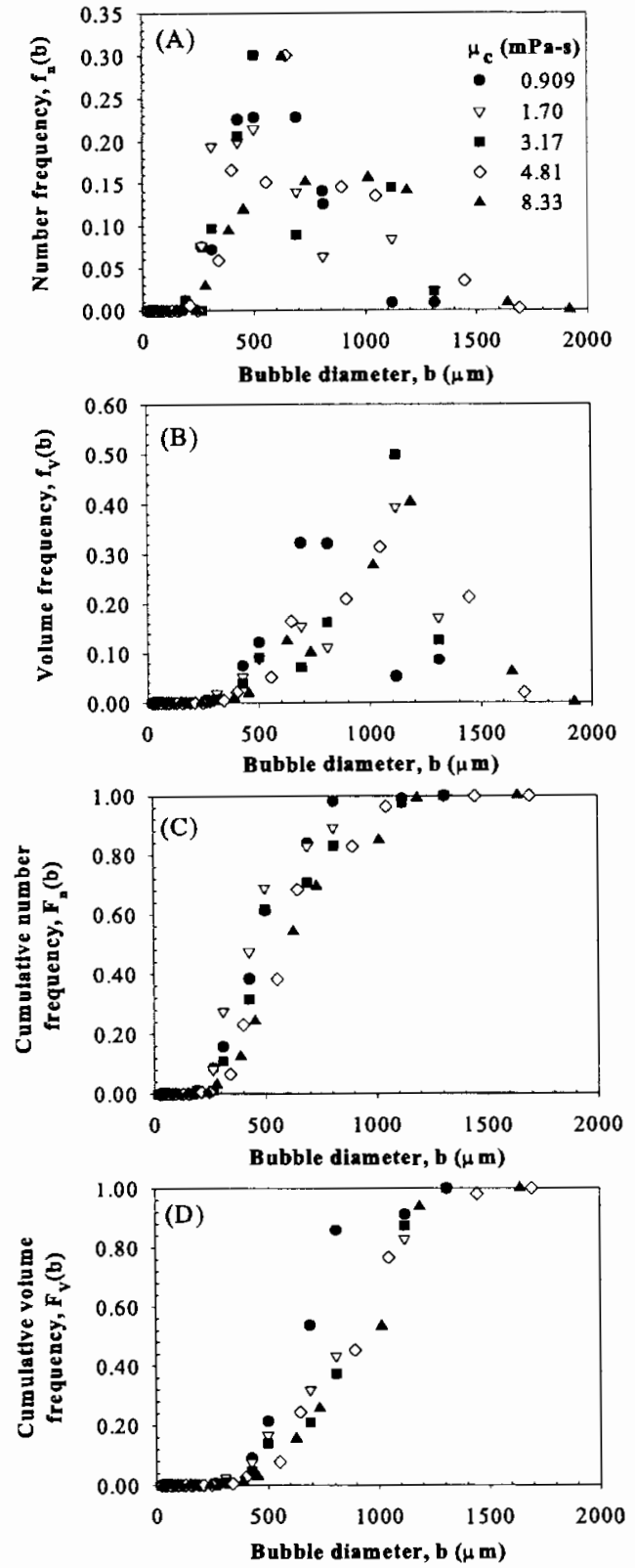

Figure 4. Effect of liquid viscosity on distribution at a gas flow rate of $74.1 \mathrm{~cm}^{3} / \mathrm{min}$ : (A) number frequency, (B) volume frequency, (C) cumulative number frequency, and (D) cumulative volume frequency.

an important factor for estimating transfer rates, the areaweighted mean diameter or Sauter mean diameter $\left(b_{32}=\Sigma b^{3} / \Sigma\right.$ $\left.b^{2}\right)$ is the appropriate diameter for discussion because it can be related to the specific surface area $\left(A_{\mathrm{s}}\right)$ and the dispersed-phase volume fraction $(\phi) .^{11,12}$ Therefore, both $b_{10}$ and $b_{32}$ will be used to provide a more meaningful discussion and interpretation of obtained data

3.1. Bubble Size Data. Sample images are shown in Figures 2 (parts $A$ and $B$ ). These images were selected from a sequence of images obtained at a sampling rate of 500 frames $/ \mathrm{s}$ at a viscosity of $8.33 \mathrm{mPa} \cdot \mathrm{s}$ and two different flow rate settings. $b_{10}$ and $\sigma_{10}$ are reported for each listed condition where $b_{10}$ increases as gas flow rate increases. Parts $A-D$ of Figure 3 illustrate different forms of BSD as a function of liquid viscosity $\left(\mu_{\mathrm{c}}\right)$ at a gas flow rate of $19.4 \mathrm{~cm}^{3} / \mathrm{min}$. The number and volume distributions are presented in the form of frequency $(f(b))$ and a cumulative frequency $\left(F(b)=\sum f(b)\right)$. Here, the subscripts $n$ 


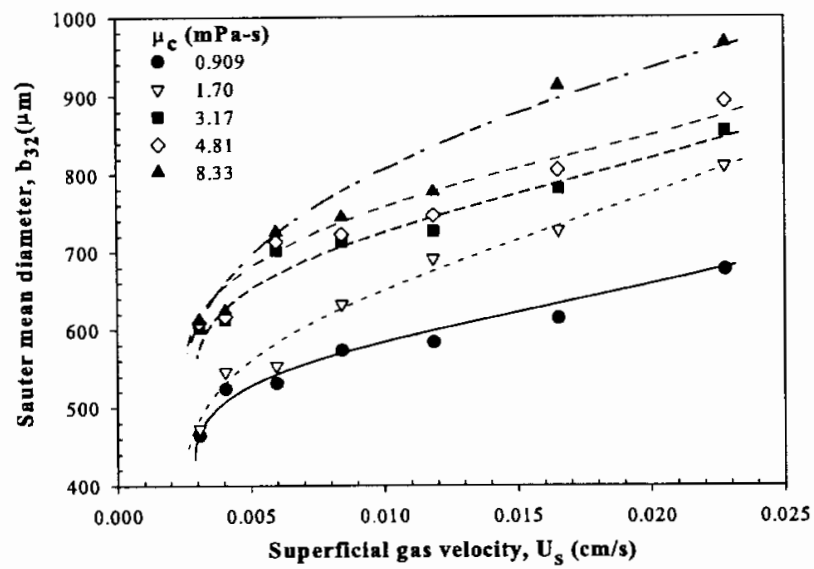

Figure 5. Plot of $b_{32}$ versus $U_{\mathrm{s}}$ to show the effect of $\mu_{\mathrm{c}}$ and $U_{\mathrm{s}}$ on $b_{32}$.

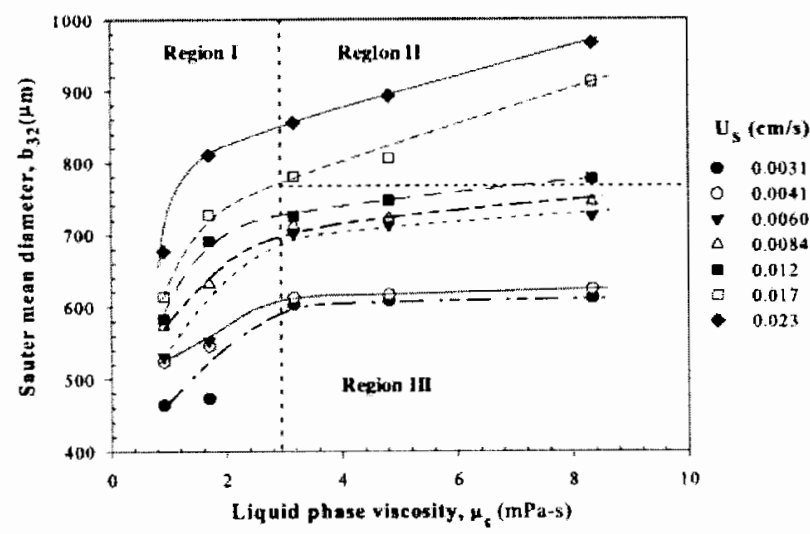

Figure 6. Plot of $b_{32}$ versus $\mu_{\mathrm{c}}$ showing simultaneous effect of $\mu_{\mathrm{c}}$ and $U_{\mathrm{s}}$ on $b_{32}$ in different regions.

and $V$ denote the number and the volume, respectively. The data show that as $\mu_{\mathrm{c}}$ increases, the distribution broadens and the number of larger bubbles increases. In addition, the number frequency shows less noise than the volume frequency. Figure 4 (parts $\mathrm{A}-\mathrm{D}$ ) shows a similar trend at the highest gas flow rate $\left(74.1 \mathrm{~cm}^{3} / \mathrm{min}\right)$. Comparing Figures $3 \mathrm{D}$ and $4 \mathrm{D}$ reveals that the effect of $\mu_{\mathrm{c}}$ on bubble distributions becomes less pronounced as the gas flow rate increases.

Figure 5 shows the plot of the Sauter mean diameter $\left(b_{32}\right)$ versus superficial velocity $\left(U_{s}\right)$, where $U_{\mathrm{s}}$ is defined as the ratio of volumetric gas flow rate to the vessel cross-sectional area. Trend lines on the figures are drawn to show the effect of $U_{\mathrm{s}}$ and $\mu_{\mathrm{c}}$ on $b_{32}$. Here, $b_{32}$ increases as both $\mu_{\mathrm{c}}$ and $U_{\mathrm{s}}$ increase. There is a sharp increase in $b_{32}$ at low $U_{\mathrm{s}}(<0.005 \mathrm{~cm} / \mathrm{s})$, showing that $U_{\mathrm{s}}$ has a stronger influence on $b_{32}$ than $\mu_{\mathrm{c}}$. This observation is similar to those reported by Marrucci and Nicodemo ${ }^{13}$ for an aqueous $\mathrm{KCl}$ solution. To better understand the competitiveness between these two parameters, $b_{32}$ versus $\mu_{\mathrm{c}}$ is plotted in Figure $6 . \ln$ this figure, the results can be subdivided into three regions. In region $\mathrm{I}\left(\mu_{\mathrm{c}}<3 \mathrm{mPa} \cdot \mathrm{s}\right)$, both $U_{\mathrm{s}}$ and $\mu_{\mathrm{c}}$ play significant roles in controlling $\mathrm{b}_{32}$. In region II $\left(\mu_{\mathrm{c}}>3 \mathrm{mPa} \cdot \mathrm{s}\right.$ and $\left.U_{\mathrm{s}}>0.012 \mathrm{~cm} / \mathrm{s}\right)$, the influence of $U_{\mathrm{s}}$ on $b_{32}$ becomes less pronounced as $\mu_{c}$ increases (the slope $\approx 19.4$ $\mu \mathrm{m} / \mathrm{mPa} \cdot \mathrm{s})$. In region III $\left(\mu_{\mathrm{c}} \geq 3 \mathrm{mPa} \cdot \mathrm{s}\right.$ and $\left.U_{\mathrm{s}} \leq 0.012 \mathrm{~cm} / \mathrm{s}\right)$, $b_{32}$ is predominantly controlled by $U_{\mathrm{s}}$; here, $\mu_{\mathrm{c}}$ has little effect on the increase in $b_{32}$ (the slope $\approx 3.9 \mu \mathrm{m} / \mathrm{mPa} \cdot \mathrm{s}$ ).

3.2. Test of Similarity of Bubble Size Distributions. A cumulative frequency was analyzed to examine the functional form of the bubble size distribution. Cumulative number and volume distributions of parts $\mathrm{C}$ and $\mathrm{D}$ of Figure 3 were selected and normalized by scaled diameter $b_{10}$ and $b_{32}$, respectively, as shown in Figure 7 (parts A and B). Self-similarity is seen in the normalized $F_{n}(b)$; that is, the normalized distribution lies on the same curve (see Figure 7A). Compared to the number distribution, self-similarity in the volume distribution (Figure 7B) is not as well-observed. Parts C and D of Figure 7 show the normalized plots of parts $C$ and $D$ of Figure 4, respectively. Again, self-similarity is seen in the normalized $F_{n}(b)$, but not completely in the normalized $F_{H}(b)$.

Therefore, the log-normal form of the continuous number frequency distribution $\left(f_{n}\right)$, normalized with respect to $b_{10}$, can be used to describe this self-similarity for obtained data sets. It is generally expressed as follows, ${ }^{11,14}$

$$
f_{n}(\beta)=\frac{1}{\sqrt{2 \pi} \sigma_{0}} \exp \left[-\frac{1}{2}\left(\frac{\ln (\beta)-\ln (\bar{\beta})}{\sigma_{0}}\right)^{2}\right] \frac{1}{\beta}
$$

where $\beta$ is the dimensionless diameter, defined as $\beta=b / b_{10}$, and $\bar{\beta}$ is the dimensionless median diameter corresponding to the dimensionless diameter for which the cumulative number distribution is 0.5 . Here, $\sigma_{0}$ can be obtained from the relation

$$
\sigma_{0}=\ln \left(\beta_{84 \%} / \beta_{50 \%}\right)
$$

where $\beta_{84 \%}$ and $\beta_{50 \%}$ are the dimensionless diameters corresponding to the 84 th and 50 th percentiles on the log-probability curve, respectively. Both $\beta$ and $\sigma_{0}$ were obtained from the bestfit curve through the data sets. The result after analyzing the data is given by

$$
\begin{aligned}
f_{n}(\beta)=\frac{1}{\sqrt{2 \pi}(0.37 \pm 0.059)} \times \\
\exp \left[-\frac{1}{2}\left(\frac{\ln (\beta)-\ln (0.99 \pm 0.030)}{0.37 \pm 0.059}\right)^{2}\right] \frac{1}{\beta}
\end{aligned}
$$

where $\bar{\beta}$ is $0.99 \pm 0.030$ and $\sigma_{0}$ is $0.37 \pm 0.059$. Figure 8 shows three variations of eq 3 plotted on semilog coordinates. A collection of data at different $\mu_{\mathrm{c}}$ and gas flow rates is shown superimposed on the curves of Figure 8 to illustrate the scatter and curve fitting involved.

3.3. Impact of Bubble Sizes on the Voltage Reading of the Solutions. The average-baseline-reading voltage $\left(V_{\mu_{\mathrm{c}}, 0}\right.$, reading in $\mathrm{mV}$ ) at each $\mu_{\mathrm{c}}$ prior to introducing bubbles was calculated and used as the reference point for calculating the percentage relative difference (PRD) at different $\mu_{\mathrm{c}}$ and $U_{\mathrm{s}}$. PRD is defined as

$$
\mathrm{PRD}=100 \times \frac{\bar{V}_{\mu_{\mathrm{c}}, U_{\mathrm{s}}}-\bar{V}_{\mu_{\mathrm{c}}, 0}}{\overline{\mathrm{V}}_{\mu_{\mathrm{c}}, 0}}
$$

where $\bar{V}_{\mu_{\mathrm{s}}, U_{\mathrm{s}}}$ is the average voltage value at the particular $\mu_{\mathrm{c}}$ and $U_{\mathrm{s}}$ condition. Figure 9 shows a plot of PRD as a function of $U_{\mathrm{s}}$ and $\mu_{\mathrm{c}}$. At $\mu_{\mathrm{c}}=0.909 \mathrm{mPa} \cdot \mathrm{s}$, PRD increases rapidly with increasing $U_{\mathrm{s}}$. The slope is $\sim 6000 \mathrm{~s} / \mathrm{cm}$. As $\mu_{\mathrm{c}}$ increases, $U_{\mathrm{s}}$ has less of an effect on PRD. It appears that the slope decreases to $\sim 2000 \mathrm{~s} / \mathrm{cm}$ for $\mu_{\mathrm{c}}>1.69$.

Another interest is to quantitatively relate PRD to the mean bubble population within the system. In this particular case, PRD is plotted against $b_{32}$ (Figure 10). Figure 10 reveals important features of the trend of PRD with respect to $b_{32}$. First, it shows that, at the lowest viscosity, bubble size has a strong impact on the voltage reading. For instance, at $\mu_{\mathrm{c}}=0.909 \mathrm{mPa} \cdot \mathrm{s}$, by changing the bubble size from $\sim 460$ to $\sim 660 \mu \mathrm{m}$ (increase by 

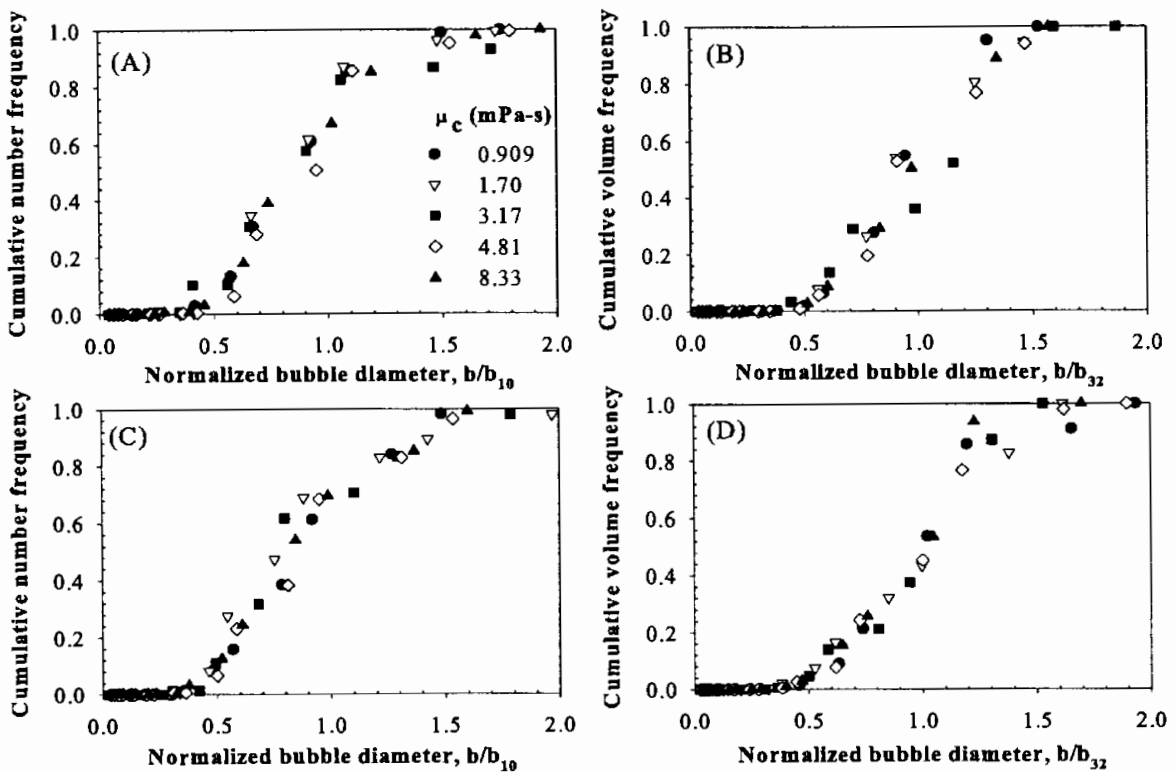

Figure 7. Cumulative distribution at (A) $19.4 \mathrm{~cm}^{3} / \mathrm{min}$, Figure $3 \mathrm{C}$ replotted with an ordinate normalized with $b_{10} ;(B) 19.4 \mathrm{~cm}^{3} / \mathrm{min}$, Figure 3D replotted with an ordinate normalized with $b_{32} ;$ (C) $74.1 \mathrm{~cm}^{3} / \mathrm{min}$, Figure $4 \mathrm{C}$ replotted with an ordinate normalized with $b_{10}$; and (D) $74.1 \mathrm{~cm}^{3} / \mathrm{min}$, Figure $4 \mathrm{D}$ replotted with an ordinate normalized with $b_{32}$.
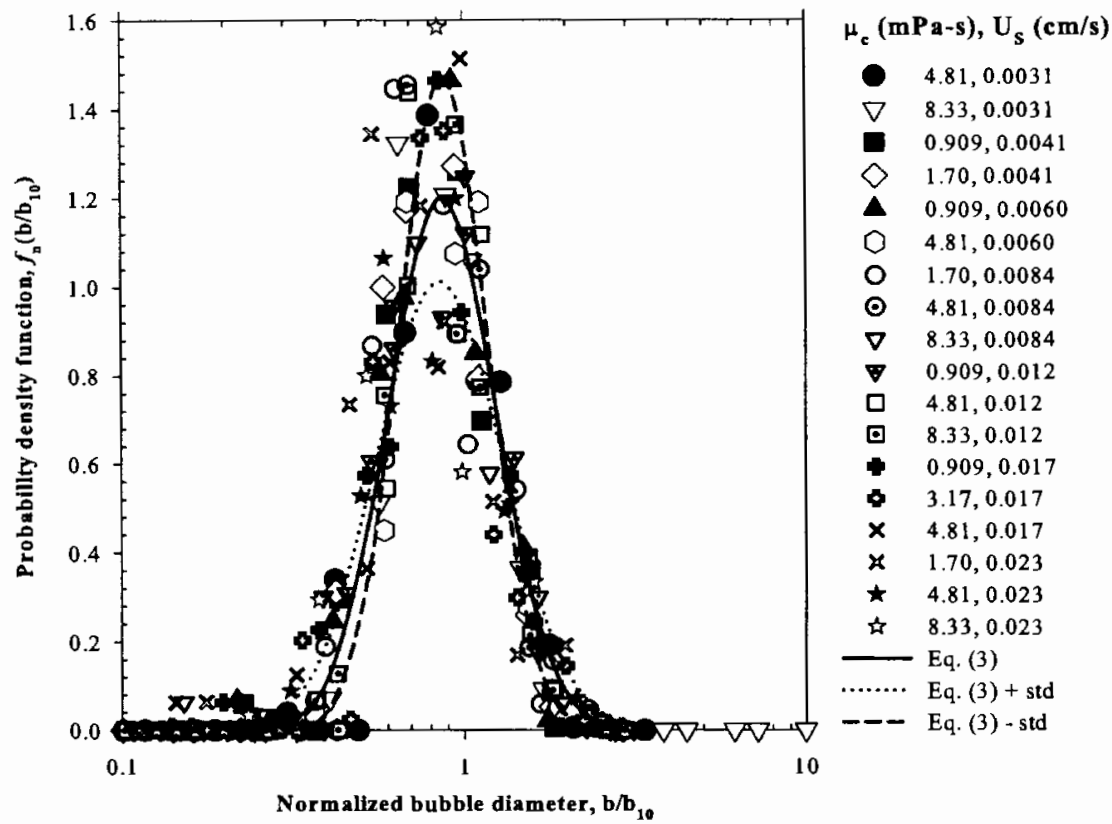

Figure 8. Similarity of normalized number distribution. The solid line is eq 3. A collection of data sets is superimposed for comparison.

$43 \%$ in mean size population), PRD changes from $0 \%$ to $180 \%$. In addition, the result indicates that, at high viscosity $\mu_{\mathrm{c}}>$ 3.17 ) with an initial $U_{\mathrm{s}}$ of $0.0031 \mathrm{~cm} / \mathrm{s}$, viscosity is the main factor controlling the voltage reading of the solution, because $b_{32}$ has no significant impact on $\mathrm{PRD}\left(\mathrm{PRD} \approx 3-5 \%\right.$ at $b_{32} \approx$ $600 \mu \mathrm{m}$, as shown in Figure 10). However, as the gas flow rate increases, the bubble size increases and starts controlling the change in PRD at this high viscosity range. Puleo and coworkers $^{15}$ observe this similar effect of bubbles on voltage reading from the optical backscatter sensors. Here, bubbles interrupt electrolyte paths causing the change in an impedance (voltage) of a reference electrode in the solution; therefore, as bubble size increases, the value of the voltage increases. The region of interest has been highlighted in Figure 10, showing the possible dynamic dependency of PRD with respect to bubble sizes. This result suggests that it may be possible to predict the bubble size in the molten salt-oxide reduction system via a voltage measurement.

3.4. Similitude to Practical Application. In this section, the rising velocity, the friction factor, and the predicted bubble size and formation were analyzed. The obtained information was used to provide a similitude to a practical application, the hot fuel dissolution apparatus (HFDA), operated at INL. 4.5

3.4.1. Rising Velocity and Friction Factor. The rising velocity of each bubble $\left(\nu_{b}\right)$ was calculated by tracking the bubble movement from a sequence of images at different 


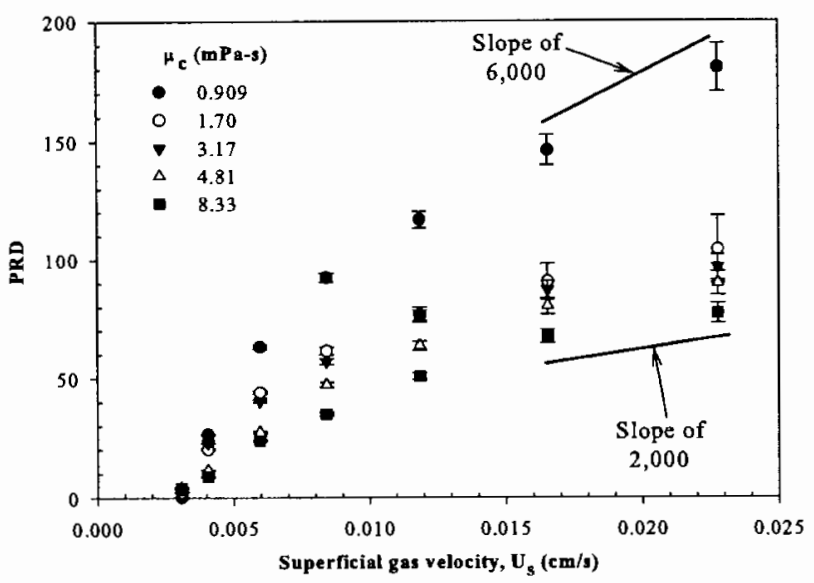

Figure 9. Percentage relative difference (PRD) versus $U_{s}$ showing the effect of $\mu_{\mathrm{c}}$ and $U_{\mathrm{s}}$ on the change in voltage response.

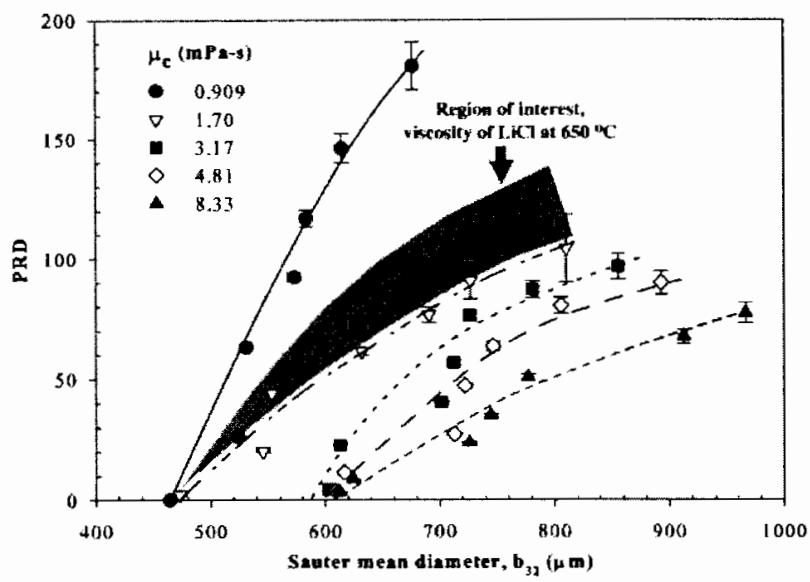

Figure 10. Percentage relative difference (PRD) versus $b_{32}$ showing the effect of $\mu_{\mathrm{c}}$ on the system matrix

conditions. The bubble Reynolds number $\left(\operatorname{Re}_{\mathrm{b}}=\rho_{\mathrm{c}} b v_{\mathrm{b}} / \mu_{\mathrm{c}}\right)$ was calculated from this information. In addition, the Fanning friction factor $(f)$ can be approximated using the following expression ${ }^{16}$

$$
\frac{f}{R e_{\mathrm{b}}}=\frac{4}{3} \frac{g \mu_{\mathrm{c}}}{\rho_{\mathrm{c}} v_{\mathrm{b}}^{3}}\left(\frac{\rho_{\mathrm{c}}-\rho_{\mathrm{b}}}{\rho_{\mathrm{c}}}\right)
$$

where $g$ is the gravitational constant and $\rho_{\mathrm{b}}$ is the bubble density. Figure 11 shows the plot of the Fanning friction factor for this experiment. The regression was run with an expression similar to an equation presented in the literature ${ }^{16}$ with power unspecified. The result is

$$
\frac{f}{R e_{\mathrm{b}}}=\frac{4.0}{\operatorname{Re}_{\mathrm{b}}{ }^{1.6}} \Rightarrow f=\frac{4.0}{R e_{\mathrm{b}}^{3 / 5}}
$$

The coefficient of determination $\left(R^{2}\right)$ of eq 6 is 0.92 , showing that the accuracy of the fit is acceptable. Equation 6 has a resemblance to the friction factor for the intermediate region $(f$ $=18.5 / R e^{3 / 5}$ for $2<R e<500$ ). This result implies that these bubbles should not be characterized by Stokes' law $f=24 / R e$ for $R e<0.1$ ). It is suspected that the constant 4.0 in eq 6 is $\sim 80 \%$ smaller than the literature constant because the velocity term used in eq 5 is different than the terminal velocity used in the classical theory. Here, the rising velocity of each bubble rises faster than the estimated terminal velocity because (1) there

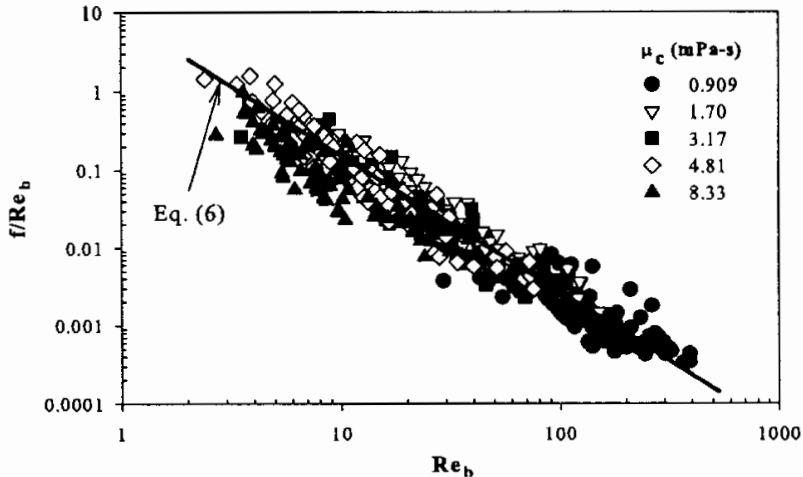

Figure 11. Friction factor for bubbles moving in different aqueous solutions with $\mathrm{NaCl}$.

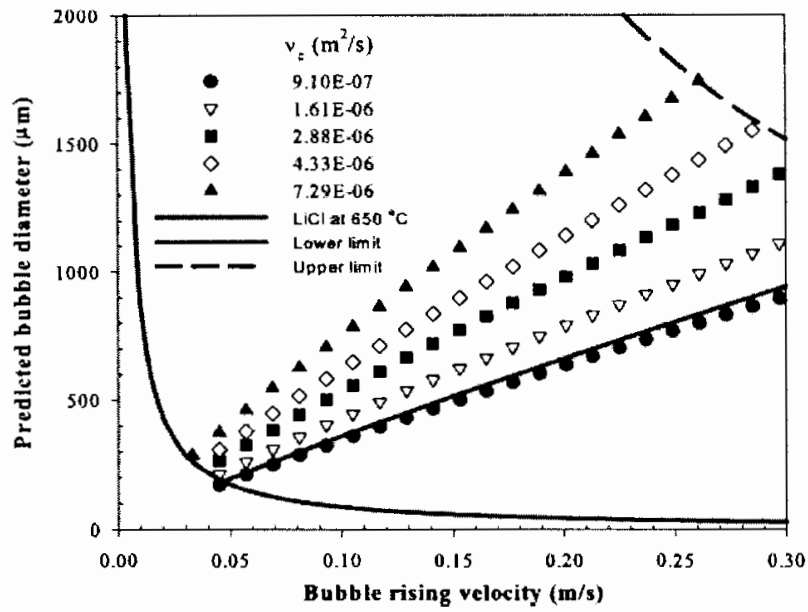

Figure 12. Calculated bubble diameter versus bubble rising velocity according to eq 7 . Kinematic viscosity $\left(\nu_{\mathrm{c}}\right)$ is calculated using the values from Table 1.

may be an influence from its neighbor (adjacent) bubbles and (2) the gas within the bubble circulates such that the surface velocity is not zero. ${ }^{17}$

By substituting eq 6 into eq 5, $b$ can be calculated based on physical properties of the system and $\iota_{\mathrm{b}}$; that is,

$$
b=0.477 v_{\mathrm{c}}^{0.375} v_{\mathrm{b}}^{0.875}\left(\frac{\rho_{\mathrm{c}}}{\rho_{\mathrm{c}}-\rho_{\mathrm{b}}}\right)^{0.625} \quad 2<R e_{\mathrm{b}}<500
$$

where $\nu_{\mathrm{c}}$ is the liquid-phase kinematic viscosity $\left(\nu_{\mathrm{c}}=\mu_{\mathrm{c}} / \rho_{\mathrm{c}}\right)$. Since the HFDA is operated at $650{ }^{\circ} \mathrm{C}$, this raises a concern on the validity of eq 7 with respect to a temperature effect on $v_{\mathrm{c}}$ and density ratio. It is believed that the predominant factor associated with temperature is the liquid-phase viscosity $\left(\mu_{c}\right)$ because (1) the density ratio in eq 7 will essentially be closer to unity $\left(\rho_{\mathrm{b}} \ll \rho_{\mathrm{c}}\right)$ and $(2)$ by changing temperature from 25 to $100{ }^{\circ} \mathrm{C}$, using water as an example, the density changes by $4 \%$ whereas the viscosity changes by $68 \%$. Therefore, by changing $\mu_{\mathrm{c}}$, which also increases $\rho_{\mathrm{c}}$ (see values listed in Table 1), $\nu_{\mathrm{c}}$ in the practical application is covered within a spectrum of this study. In addition, the $v_{\mathrm{c}}$ valucs of water at room temperature and $\mathrm{LiCl}$ at $650^{\circ} \mathrm{C}$ are essentially identical $(\sim 1)$. Figure 12 shows the plot of eq 7 at various conditions. The solid and dashed trend lines show the lower and upper limits of eq 7 , respectively.

3.4.2. Prediction of Bubble Sizes via Dimensional Analysis and Newton's Second Law of Motion. To further relate this 
work to the practical application done in the HFDA, it is important to understand the formation of bubbles on the electrode surface. However, the difficult part is how to combine both hydrodynamic and electrochemical phenomena. From the hydrodynamic side, consider the problem of a bubble forming at a small orifice (assuming that the surface of the anode is made up of small porous holes) in a continuous-phase solution. There is effectively a flow of the gas through the orifice. The bubble grows slowly until its buoyancy exceeds the balancing force due to surface tension. The goal is to know the size of the bubble when it breaks away from the orifice. From this idea, in general, a list of relevant parameters can be drawn as follows: bubble volume ( $V$ )-which can be related to bubble diameter if the bubble is of a spherical form, orifice diameter $\left(d_{\mathrm{o}}\right)$, liquid density $\left(\rho_{\mathrm{c}}\right)$, bubble density $\left(\rho_{\mathrm{b}}\right)$, liquid/gas surface tension $(\sigma)$, gravity $(g)$, liquid viscosity $\left(\mu_{\mathrm{c}}\right)$, and average linear velocity of efflux of the gas as it crosses the end of the orifice and forms the drop $(U)$. For most practical purposes, gas viscosity $\left(\mu_{\mathrm{b}}\right)$ is extremely small compare to liquid viscosity $\left(\mu_{\mathrm{b}} \ll \mu_{\mathrm{c}}\right)$; therefore, $\mu_{\mathrm{b}}$ can be disregarded in this analysis. Since $\rho_{\mathrm{b}} \ll \rho_{\mathrm{c}}, \Delta \rho=\rho_{\mathrm{c}}-\rho_{\mathrm{b}}$ is used instead to account for the hydrodynamic difference. Three recurring parameters can be selected from this list, which are $d_{0}, \sigma$, and $\Delta \rho$. From the dimensional analysis, the dimensionless drop volume $\left(V^{*}\right)$ can be expressed in the following functional relationship: ${ }^{6}$

$$
V^{*} \equiv \frac{V}{d_{0}^{3}}=f\left[U \sqrt{\frac{\Delta \rho d_{0}}{\sigma}}, \frac{\Delta \rho g d_{0}^{2}}{\sigma}, \frac{\mu}{\sqrt{\Delta \rho \sigma d_{0}}}\right]
$$

After squaring the first group in the right-hand side of eq 8 , it yields the Weber number ( $W e=\Delta \rho U^{2} d_{0} / \sigma$ ). This group determines the nature of the interaction of inertial and surface forces. A small value of $W e$ implies that the surface force is significant. The second group is the Bond number $(B o)$. It is used to determine the competitiveness between gravitational and surface forces. The last group is a dimensionless viscosity showing the relative influence between viscous and surface forces.

The next step is to develop an equation that explains the formation of a spherical bubble at an orifice by applying Newton's second law of motion. ${ }^{18,19}$ By assuming that the rate change of bubble mass is negligible $(\mathrm{d} m / \mathrm{d} t \approx 0)$, the net forces ean be given by

$$
\Delta \rho g V+\frac{\pi d_{\mathrm{o}}^{2}}{4}\left(p_{i}-p\right)=\pi d_{\mathrm{o}} \sigma+F+m^{\prime} \frac{\mathrm{d} v}{\mathrm{~d} t}
$$

The first and second terms on the left-hand side are the net buoyancy force and the excess pressure force $\left(p_{i}\right.$ is the static pressure of the gas stream at the exit level and $p$ is the pressure in the liquid at the level of the top of the orifice), respectively. These terms are balanced by the surface force $\left(\pi d_{0} \sigma\right)$, the drag force $(F)$, and the foree required to overcome the inertia of the surrounding fluid on the bubble. In the last term, $m^{\prime}$ represents the mass term for the displaced fluid from the bubble that is instantaneously replaced by another bubble. Equation 9 is expressed such that the vertical direction is taken as positive.

For a general large system, the pressure would be constant and the term $p_{i}-p$ can be expressed in terms of bubble diameter itself,

$$
p_{i}-p=\frac{4 \sigma}{b}
$$

By assuming that, during the formation stage, the ratio of inertial force to viscous force is small $(<0.1)$, then $F$ would yield the typical experimental drag force given in the literature, ${ }^{16,18}$

$$
F=3 \mu_{c} v \pi b
$$

The last term in eq 9 can be interpreted mathematically by assuming that a bubble grows radially in all directions such that the changing rate in bubble volume is equivalent to the volumetric gas flow rate. Then, this term becomes

$$
m^{\prime} \frac{\mathrm{d} v}{\mathrm{~d} t}=-\frac{4 \Delta \rho V v^{2}}{b}
$$

With these terms, eq 9 can be expressed in the dimensionless form; that is,

$$
\frac{1}{6} B o \cdot D^{3}+\frac{2}{3} W e \cdot D^{2}-3 C a \cdot D+D^{-1}-1=0
$$

where the Bond number $(B o)$ is defined by $B o=\Delta \rho g d_{0}{ }^{2} / \sigma$, the Weber number $(W e)$ is defined by We $=\Delta \rho U^{2} d_{0} / \sigma$, the Capillary number (Ca) is defined as $C a=\mu_{\mathrm{c}} v / \sigma$, and $D$ is the dimensionless diameter, $D=b / d_{0}$. Equation 13 contains the dimensionless groups suggested by eq $8 . \mathrm{Ca}$ is derived by combining the Weber number group and the dimensionless viscosity group. In fact, $\mathrm{Ca}$ is a dimensionless velocity that has surface tension in it; it is independent of a length scale. Equation 13 is essentially based on the bubble formation through the orifice. The velocity-the radial growth rate $(v)$-can be determined by dividing the volumetric gas flow rate by the bubble surface area.

The next approach is to apply the electrochemistry side to the above formulation. In the actual application, current density can be used to determine the gas velocity through the platinum anode surface. For the $\mathrm{O}_{2}$ case where $2 \mathrm{O}^{2-}+4 \mathrm{e}^{-} \rightarrow \mathrm{O}_{2}(\mathrm{~g})$, a nominal current of $3 \mathrm{~A}$ for the $\mathrm{LiCl}$ operating at $650{ }^{\circ} \mathrm{C}\left(\mu_{\mathrm{c}}=\right.$ $1.5 \mathrm{mPa} \cdot \mathrm{s})$ can be applied and the generated volumetric gas rate can be calculated: 4,5

$$
\begin{array}{r}
3 \mathrm{~A} \times \frac{1 \mathrm{C} / \mathrm{s}}{1 \mathrm{~A}} \times \frac{1 \mathrm{e}^{-}}{1.6 \times 10^{-19} \mathrm{C}} \times \frac{1 \mathrm{O}_{2} \text { atom }}{4 \mathrm{e}^{-}} \times \\
\frac{1 \mathrm{~mol} \mathrm{O} 2}{6.022 \times 10^{23} \text { atom }} \times \frac{75.7 \mathrm{~L}}{1 \mathrm{~mol}} \times \frac{1000 \mathrm{~cm}^{3}}{1 \mathrm{~L}}= \\
0.588 \mathrm{~cm}^{3} / \mathrm{s} \text { or } 35.3 \mathrm{~cm}^{3} / \mathrm{min}
\end{array}
$$

Since the platinum anode in the system has the surface area of $15.95 \mathrm{~cm}^{2}$, the velocity $(v)$ is $0.0369 \mathrm{~cm} / \mathrm{s}$. The current density for this case is $\sim 188 \mathrm{~mA} / \mathrm{cm}^{2}$. Janssen ${ }^{20}$ reports that the oxygen bubbles rising from a platinum electrode are $\sim 0.021 \mathrm{~cm}(210$ $\mu \mathrm{m})$ in diameter at $200 \mathrm{~mA} / \mathrm{cm}^{2}$. Although that study is based on both hydrogen- and oxygen-evolving electrodes in alkaline solution at $25^{\circ} \mathrm{C}$, it provides an approximate range of oxygen sizes evolving from a platinum anode. Current density of the electrode and the flow velocity of electrolyte near the electrode have a substantial effect on the bubble sizes. In a nonagitated electrolyte, the bubble diameter can increase as the current density decreases. ${ }^{21}$ Therefore, by increasing the surface area of an electrode, the size of bubbles would increase with respect to a constant nominal applied current.

Knowing that $v=3.69 \times 10^{-4} \mathrm{~m} / \mathrm{s}$, eq I 3 can be used to solve for an appropriate $D$ by providing different values of $d_{0}$. From dimensional analysis, it is important not to lose focus of the magnitude of forces used in deriving eq 13. With initial inspection, it is evident that values of $W e$ and $B o$ will be small because of the surface foree. This implies that $b$ will essentially 


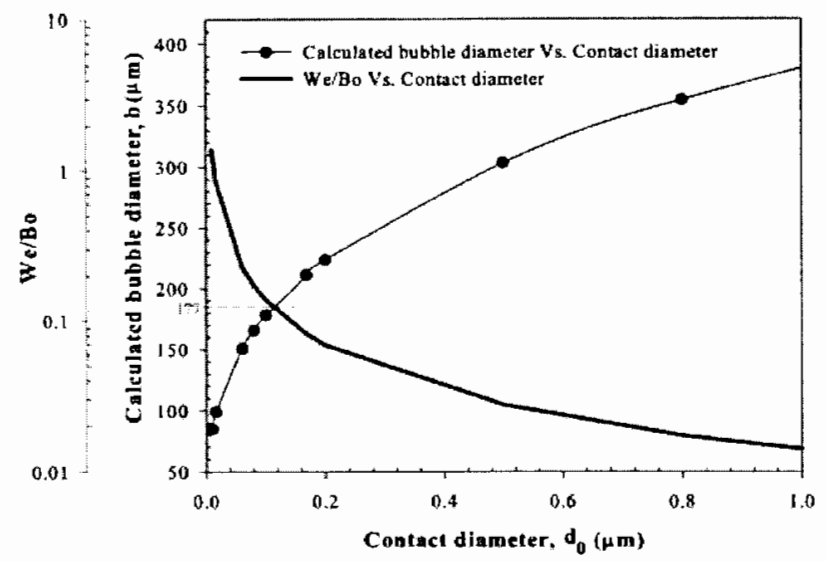

Figure 13. Assessment of $b$ with respect to $d_{0}$ at efflux velocity of 0.00037 $\mathrm{m} / \mathrm{s}$ under the influence of inertial and gravitational forces.

grow to be very large in comparison to the initial $d_{0}\left(d_{0} / b \ll 1\right)$ before overcoming the surface force. From this analysis, $D^{-1}$ in eq 13 can be omitted and this results in

$$
\frac{1}{6} B o \cdot D^{3}+\frac{2}{3} W e \cdot D^{2}-3 C a \cdot D-1=0
$$

which can be solved analytically using cubic coefficient substitution. The solution of eq 15 is

$$
D=-\left[\sqrt[3]{\frac{1}{2}+\sqrt{\frac{t^{2}}{4}+\frac{s^{2}}{27}}}+\sqrt[3]{\frac{1}{2}-\sqrt{\frac{t^{2}}{4}+\frac{s^{2}}{27}}}\right]
$$

where $s=-(16 / 3)(W e / B o)^{2}-(18 C a / B o)$ and $t=(128 / 27)-$ $(\mathrm{We} / \mathrm{Bo})^{3}+\left(24 \mathrm{We} \cdot \mathrm{Ca} / \mathrm{Bo}^{2}\right)-(6 / \mathrm{Bo})$. The range of the solution must be considered based on the ratio of We to $B o$. We/Bo should be $>0.01$, because current density provides the mechanism of bubble formation (i.e., inertial force). For very small $W e / B o$, the system is dominantly controlled by gravitational force, which is misleading in the practical application. Figure 13 shows the resulting plot of $b$ versus $d_{0}$ under the influence of $W e / B o$ at $v=0.000369 \mathrm{~m} / \mathrm{s}$. The result indicates that the bubble size increases as $W e / B O$ decreases and the critical bubble size is $\sim 177 \mu \mathrm{m}$. The critical size is determined based on the intersection between the curves of $b$ versus $d_{0}$ and $W e / B o$ versus $d_{0}$. This is close to the value of $210 \mu \mathrm{m}$ at $200 \mathrm{~mA} / \mathrm{cm}^{2}$ reported by Janssen. ${ }^{20}$ In addition, Figure 13 indicates that the average departure bubble sizes can range from 85 to $405 \mu \mathrm{m}$ at this efflux velocity condition. The variation of bubble size at each condition depends on the variation of $d_{0}$, which can be dependent upon various parameters such as concentration, potential of the electrode, wetting conditions, surface roughness, and shape and shielding factors. ${ }^{20-22}$

3.4.3. Bubble Formation and Movement-Potential Situation in an Electrochemical Cell. The current study has shown that, after bubbles detach from the material surface, they may not rise per Stokes' Law. It is important to keep in mind that terminal velocity under that assumption is considerably accurate if bubbles are not interfering with each other, i.e., at least $\sim 3 d$ apart. ${ }^{17}$ In the proposed derivation, the volume rate of each bubble can be approximated mathenatically, and the number of bubbles generated along the surface can bc calculated by dividing the total gas flow rate by this value. The outcome shows that there may be 3000-70 000 bubbles generated on the anode surface depending on the size of $d_{0}$ available on the surface.
This result supports this proposed argument. Therefore, Figure 13 (based on eq 7) can be used to obtain the rising velocity.

In a mass transfer derivation and diffusion layer theory, it is often assumed that all bubbles are the same size. ${ }^{20,23}$ However, the distribution of bubble sizes exists under the real condition, as shown from the current experiment and other studies..$^{20-22}$ From this perspective, the use of $b_{32}$ is preferred over $b_{10}$. The current experiment has shown that $b_{32}$ is linearly proportional to $b_{10}$ and it is roughly $b_{32}=1.3 b_{10}$. The range of $b_{32}$ in the practical system can be predictcd and ranges from 117 to 520 $\mu \mathrm{m}$.

Overall, this suggests a new way or a potential of interpreting how evolved gas bubbles affect the efficiency. First, the current study has indicated that, at a constant gas flow rate, bubble population density is not monodispersed in nature. The analysis of bubble formation supports this observation by showing different possible bubble sizes depending on $d_{0}$ under a constant current density. The behavior of bubbles on electrodes alters the availability of the anode surface area, the numbers of generated bubbles, and the bubble rising velocity. It is suspected that these different variations alter sizes of bubbles because of the change in electrolyte distribution on a surface area of bubbles under an electrochemical effect. ${ }^{22-25}$ For example, a bubble can attach to another bubble and change an elcctrolyte distribution via coalescence. Furthermore, with the assumption that a bubble rising velocity is higher than the predicted Stokes' velocity and the fact that surface force is predominant in the practical system $\left(1.50 \times 10^{-11} \leq W e \leq 1.80 \times 10^{-9}\right.$ and $1.08 \times 10^{-11} \leq B o \leq$ $1.56 \times 10^{-7}$ ), it is believed that these bubbles can form a layer. Definitely, bubbles will burst up at the free surface and cause splashing at the interface, which is observed in the HFDA operation. Surface tension may prevent small bubbles from bursting at the interface freely, while large bubbles have a higher probability of bursting and sending up jets of electrolyte droplets. It is suspected that the existence of a bubble layer at the interface and bubbles around the anode are the potential cause of the efficiency drop in the system.

\section{Conclusions}

This mock-up study highlighted and provided characteristics of bubbles near a reference electrode. The information was analyzed and used to provide a similitude to a practical application. A fundamental equation was developed to aid the understanding of the formation of a spherical bubble by applying Newton's second law of motion. The key conclusions based on this study are the following:

- The bubble size increases with liquid viscosity and superficial velocity. The bubble distribution is not monodispersed. Self-similarity is seen and can be characterized by the log-normal form of the continuous number frequency distribution.

- The liquid viscosity plays an important role in controlling the voltage reading of the solution at the lowest gas flow rate. As the gas flow rate increases, the bubble size increases and starts controlling the change in voltage reading. This observation is similar to the study reported by Puleo and co-workers ${ }^{15}$ on the effect of bubbles on voltage from the optical backscatter sensors. It is believed that bubbles can interrupt electrolyte paths in the solution, altering the voltage reading of a reference electrode.

- The analysis on bubble rising velocity reveals that the system goes through an internediate region and suggests that Stokes' Law should be used cautiously as an assumption for 
numerical simulation or bubble estimation via other types of indirect measurement technique.

- The bubble size during its formation is the function of three dimensionless groups ( $\mathrm{We}, \mathrm{Bo}$, and $\mathrm{Ca}$ ) from the dimensional analysis and the developed fundamental equation.

- The result indicates that the critical bubble size is $\sim 177$ $\mu \mathrm{m}$ after applying the electrochemistry aspect to the fundamental equation, eq 13. This value is strikingly similar to a value reported in the literature. ${ }^{20}$ The result further suggests that the average departure bubble size ranges from 85 to $405 \mu \mathrm{m}$ based on operated current density.

- From the analysis, it is suspected that there may be $3000-$ 70000 bubbles generated on the anode surface depending on the size of initial bubbles. The current results and above analysis can be used to explain a potential cause of the efficiency drop within the system.

\section{Notation}

$A_{\mathrm{s}}=$ specific surface area

$b=$ bubble diameter

$b_{10}=$ number mean diameter

$b_{32}=$ Sauter mean diameter or area-weighted mean diameter of the bubble

$b_{\max }=$ maximum bubble size

$B o=$ Bond number

$C a=$ Capillary number

$d_{0}=$ orifice diameter

$D=$ dimensionless diameter, defined as $D=b / d_{0}$

$f=$ Fanning friction factor

$F=$ drag force

$f(b)=$ continuous frequency distribution of bubble size $b$

$f(b)=$ frequency function of bubble size $b$

$F(b)=$ cumulative frequency of bubble size $b$

$g=$ gravitational constant

$m^{\prime}=$ mass term for the displaced fluid from the bubble

$p=$ pressure in the liquid at the level of the top of the orifice

$p_{i}=$ static pressure of the gas stream at the exit level

$R e_{\mathrm{b}}=$ bubble Reynolds number

$t=$ time

$U=$ average linear velocity of efflux of the gas crossing the end of the orifice

$U_{\mathrm{s}}=$ gas superficial velocity

$v=$ radial growth rate

$\nu_{\mathrm{b}}=$ bubble rising velocity

$V=$ bubble volume

$V^{*}=$ dimensionless drop volume, defined as $V^{*}=V / d_{0}{ }^{3}$

$\bar{V}=$ average-baseline-reading voltage

$W e=$ Weber number

\section{Greek Letters}

$\beta=$ dimensionless bubble diameter, defined as $\beta=b / b_{10}$

$\bar{\beta}=$ dimensionless median diameter at which $F_{n}(\beta)=0.5$

$\phi=$ dispersed-phase volume fraction

$\mu_{\mathrm{b}}=$ gas viscosity or bubble viscosity

$\mu_{\mathrm{c}}=$ liquid-phase viscosity

$\nu_{\mathrm{c}}=$ liquid-phase kinematic viscosity

$\rho_{\mathrm{b}}=$ bubble density

$\rho_{\mathrm{c}}=$ liquid-phase density

$\sigma=$ surface tension

$\sigma_{0}=$ standard deviation defined by eq 2

$\sigma_{10}=$ variance of the number mean diameter

\section{Subscripts}

$n=$ number

$V=$ volume

\section{Literature Cited}

(1) Laidler, J. J.; Battles, J. E.; Miller, W. E.; Ackeman, J. P.; Carls, E. L. Development of pyroprocessing technology. Prog. Nucl. Energy 1997 , 31,121 .

(2) Benedict, R. W.; McFarlane, H. F. EBR-Il Spent Fuel Treatment Demonstration Project Status. RADWASTE 1998. 5, 23.

(3) Simpson, M. F.; Goff, K. M.; Johnson S. G.; Bateman, K. J.; Battisti, T. J.; Toews, K. L.; Frank, S. M.; Moschetti, T. L.; O'Holleran, T. P. A description of the ceramic waste form production process from the demonstration phase of the electrometallurgical treatment of EBR -11 spent fuel. Nucl. Technol. 2001, 134, 263.

(4) Herrmann, S. D.; Li, S. X.; Simpson, M. F.; Wahlquist, D. R. Electrolytic reduction of spent oxide fuel-Bench-scale test preparations In Proc. ANS Fifth Topical Meeting on DOE Spent Nuclear Fuel and Fissile Materials Management; Sept 2002.

(5) Herrmann, S. D.; Li, S. X.; Simpson, M. F. Electrolytic reduction of spent oxide fuel--Bench-scale test results. Proc. Global, 2005, Oct (488).

(6) Middleman, S. An Introduction to Fluid Dynamics; John Wiley \& Sons: New York, 1998; pp 19-21, 45, 100.

(7) CRC Handbook of Chemistry and Physics, 85th ed.; Lide, D. R., Ed.; CRC Press: Boston, MA, 2004-2005; pp 4-22 and 6-184.

(8) Metals Reference Book; Smithells, C. J., Ed; Butterworth \& Co Ltd: Boston, MA, 1976; pp 242-290.

(9) Lessard, R. R.; Zieminski, S. A. Bubble coalescence and gas transfer in aqueous electrolytic solutions. Ind. Eng. Chem. Fundam. 1971, 10, 260.

(10) Prince, M. J.; Blanch, H. W. Bubble coalescence and break-up in air-sparged bubble columns. $A I C h E J .1990,36,1485$.

(11) Crowe, C.; Sommerfeld, M.; Tsuji, Y. Multiphase flow's with droplets and particles; CRC Press: Boston, MA, 1998; pp 37-47.

(12) Calderbank, P. H. Physical rate processes in industrial fermentation Part I: The interfacial area in gas-liquid contacting with mechanical agitation. Trans. Inst. Chem. Eng. 1958, 36, 443.

(13) Marrucci, G.; Nicodemo, L. Coalescence of gas bubbles in aqueous solutions of inorganic electrolytes. Chem. Eng. Sci. 1967, 22, 1257.

(14) Phongikaroon, S. Drop size distribution for liquid-liquid dispersions produced by rotor-stator mixers. Ph.D. Thesis, University of Maryland, College Park, Maryland, 200I; pp 62-84.

(15) Puleo, J. A.; Johnson, R. V.; Holland, K. T. Laboratory investigation of the effect of bubbles on optical backscatter sensors. Eos. Trans. AGU, Ocean Sci. Meet. Suppl. 2004, 84 (52), Abstract OS52B-10.

(16) Bird, R. B.; Stewart, W. E.; Lightfoot, E. N. Transport Phenomena; John Wiley \& Sons: New York, 1960; pp 180-196.

(17) Treybal, R. E. Mass-Transfer Operation; McGraw-Hill Book Company: London, 1980; pp 60-70.

(18) Hayes, W. B., III; Hardy, B. W.; Holland, C. D. Formation of gas bubbles at submerged orifices. AfChE J. 1959, 5, 319.

(19) Sullivan, S. L., Jr.; Hardy, B. W.; Holland, C. D. Formation of air bubbles at orifices submerged beneath liquids. AlChE J. 1964, 10, 848

(20) Janssen, L. J. J. Mass transfer at gas evolving electrodes. Electrochim. Acta 1978, 23,81.

(21) Vogt, H. The problem of the departure diameter of bubbles at gasevolving electrodes. Electrochim. Acta 1989, 34, 1429.

(22) Janssen, L. J. J. Behaviour of and mass transfer at gas evolving electrodes. Electrochim. Acta 1989, 34, 161.

(23) Janssen, L. J. J.; Hoogland, J. G. The effect of electrolytically evolved gas bubbles on the thickness of the diffusion layer. Electrochim. Acta 1970, 15, 1013.

(24) Vogt, H. The rate of gas evolution at electrodes. I. An estimate of the efficiency of gas evolution from the supersaturation of electrolyte adjacent to a gas-evolving electrode. Electrochim. Acia 1984, 29, 167.

(25) Boissonneau, P.; Byme, P. An experimental investigation of bubbleinduced free convection in a small electrochemical cell. J. Appl. Electrochem. 2000, 30, 767 . 